ORIGINAL RESEARCH ARTICLE

\title{
Gender Differentials and Disease-Specific Cause of Infant Mortality: A Case Study in an Urban Hospital in Accra, Ghana
}

\author{
Awolu Adam \\ Department of Family and Community Health, School of Public Health, University of Health and Allied Sciences. PMB 31, Ho. \\ Ghana \\ *For Correspondence: Email: awolu.adam74@gmail.com; Phone: +233243961396; +233504049606
}

\begin{abstract}
Infant mortality is a major public health problem especially in developing countries. It is an indicator of quality of and accessibility to primary healthcare as well as the overall health status of a country. Understanding the risk factors for infant mortality is the first important step to reducing its incidence/prevalence. This study examined the prevalence and disease-specific causes of infant mortality in an urban hospital in Ghana and gender differences in the burden of infant mortality. Births and deaths data at the hospital were reviewed and analyzed. Results indicated infant mortality of 32/1000 live births and highlighted malaria, severe anemia, and neonatal sepsis as the leading causes of infant deaths. Gender differences in infant mortality was not statistically significant $(\mathrm{X} 2$; P-value=0.73). It is critical to strengthen existing malaria control programs for infants and develop targeted interventions to improve infant nutrition for high risk infants. (Afr J Reprod Health 2016; 20[2]: 104-110).
\end{abstract}

Keywords: Infant, mortality, Ghana, malaria, gender

\section{Résumé}

La mortalité infantile est un problème majeur de santé publique surtout dans les pays en développement. Il est un indicateur de la qualité et de l'accessibilité aux soins de santé primaires ainsi que l'état général de santé d'un pays. Comprendre les facteurs de risque pour la mortalité infantile est la première étape importante à réduire son incidence / sa prévalence. Cette étude a examiné les causes de la prévalence et des maladies spécifiques de la mortalité infantile dans un hôpital urbain au Ghana et les différences entre les sexes dans le fardeau de la mortalité infantile. Les données sur les naissances et les décès à l'hôpital ont été examinées et analysées. Les résultats ont montré une mortalité infantile de 32/1000 naissances vivantes et ont mis en évidence le paludisme, l'anémie sévère, et la septicémie néonatale comme étant les principales causes de la mortalité infantile. Les différences entre les sexes dans la mortalité infantile n'a pas été statistiquement significative $(\mathrm{X} 2$; valeur $\mathrm{P}=0,73)$. Il est essentiel de renforcer les programmes de lutte contre le paludisme qui existent actuellement pour les enfants et d'élaborer des interventions ciblées pour améliorer la nutrition pour les enfants à risque élevé. (Afr J Reprod Health 2016; 20[2]: 104-110).

Mots-clés: Infantile, la mortalité, le Ghana, le paludisme, le sexe.

\section{Introduction}

Infant mortality is a critical public health concern worldwide and one of the key indicators of the quality of primary health delivery systems and the overall health status of a nation. An infant is helpless of him/herself, highly vulnerable, and completely dependent on others for care and development, and survival. Millions of infants have died and continue to die from various causes many of which are preventable. Traditionally, diarrheal diseases have been the most common causes of infant mortality. Diarrheal is one of the top five preventable killers of children under five years old in developing countries and most dangerous for the young, with about $90 \%$ of deaths from diarrhea occurring in small children $^{1,2}$.

The rates of infant mortality have been significantly reduced in the developed world mainly due to improvements in basic health care and technological advances in the medical field. However, infant mortality remains a cause for major concern in developing countries especially in sub-Saharan Africa. Sub-Sahara remains the most difficult place in the world for a child to survive until age five ${ }^{16}$. In 2006, the under-five mortality rate for sub-Saharan Africa was 160 per 1,000 live births, meaning that roughly 1 in every 6 children failed to reach his/her fifth birthday ${ }^{3}$. This represented a $14 \%$ reduction since 1990 but remains by far the highest rate of under-five 
mortality in the world ${ }^{4}$. West Africa has been hit the hardest with under-five mortality in Africa and the world at large. West Africa accounted for more than $40 \%$ of Africa's child deaths in 2006 constituting 2.1 million children ${ }^{5}$. The Central Intelligence Agency world infant mortality rankings for 2007 showed clearly that infant mortality rates in sub-Saharan African countries are tens to hundreds of times that of industrialized countries. From the rankings, Angola, Sierra Leone, Liberia and Ghana had 184.44, 158.27, 149.73 and 53.56 deaths per 1000 live births respectively $^{6,7}$. This same ranking had infant mortality rates for United States, United Kingdom, Norway, and Singapore at 6.37, 5.01, 3.64 and 2.30 per 1000 live births respectively ${ }^{6}$. The WHO reported that rural infants, infants of uneducated mothers, and infants in poorer households continue to have higher mortality ${ }^{5}$. There are also gender differentials in infant mortality where mortality rates may be higher for males than females in one country or community and vice versa in another. The risk factors for such differentials may be biological, social, behavioral, or a combination of all three.

As a sub-Saharan country, Ghana faces huge problem of reducing infant mortality rates as lack of sturdy improvement in child survival and development in Ghana was reported in the Ghana Demographic and Health Survey (GDHS $)^{8}$. The GDHS (2003) reported that infant mortality rates were $77,66,57,64$, per 1000 live births for the years 1988, 1993, 1998, 2003 respectively $^{8}$. The CIA ranked Ghana as the 52nd in the world with infant mortality rate of 53.56 per 1000 live births in $2007^{6,7}$. Compared to many countries in Africa such as Angola, Ghana's rate is relatively lower but nevertheless constitutes a major health concern in Ghana. Variations within the country are more disturbing than variations between Ghana and some countries in West Africa. For instance, in the CIA rankings, the national infant mortality rate in 2007 was 53.56 deaths per 1000 live births for Ghana with different rates for males $(56.64 / 1000)$ and females $(47.85 / 1000)^{6}$. In Ghana, there are also variations in infant mortality rates based on socio-economic factors especially rural-urban and regional economic differences. Also the GDHS of 2003 reported 55/1000 live births for urban areas and 70/1000 live births for rural areas ${ }^{5}$. Regional differences also exist in Ghana and were captured in GDHS of 2003. The regional infant mortality rates for Greater Accra,
Upper East, Northern, Volta, Ashanti, and Upper West were 45/1000, 33/1000, 69/1000, 75/1000, $80 / 1000$ and $105 / 1000$ live births respectively for the same period ${ }^{10}$. It is clear from the above that infant mortality in Ghana and rural areas in particular is alarming and represents many factors surrounding birth but not limited to; the health of the mother, prenatal care, quality health services delivered to the mother and infant and child care.

Many factors account for infant mortality in all societies but these factors vary between developed and less developed countries and between rural and urban centers within individual countries. In Healthy People 2010 document, for example, four causes account for more than half of all infant deaths in the United States: birth defects, disorders relating to short gestation and unspecified low birth weight, sudden infant death syndrome (SIDS), and respiratory distress syndrome ${ }^{9}$. The world health organization (WHO) also reported that neonatal diseases account for a quarter of infant and child deaths in WHO Africa region and that malaria and diarrhea account for $18 \%$ and $17 \%$ respectively ${ }^{5}$.

The Ghana integrated child health campaign reported that about 80,000 children do not live to celebrate their fifth birthday and that most of these children die from preventable causes ${ }^{10}$. The report indicated for instance, that malaria is hyper-endemic in Ghana and claims one-quarter of all under-five deaths annually. Public Agenda, a popular Ghanaian newspaper, quoted the minister of health 'For every 100 children born in Ghana, twelve die before their fifth birthday. Malaria, which affects 3.5 million people yearly, continues to be the leading killer of Ghanaian children"11. Even though infant mortality is generally decreasing in Ghana, it is important to note that neonatal mortality has increased since the late $1980 \mathrm{~s}^{12}$. For example, neonatal mortality rate averaged 43 deaths per 1000 live births in 2003 which is an increase from 38/1000 in 1988 and $39 / 1000$ in $1998^{12}$. It can therefore, be argued that neonatal mortality rate is now making up a greater proportion of infant deaths in Ghana.

Reducing infant mortality in Ghana and especially bridging the disparity gap between rural and urban centers is one of the priority goals of Ministry of Health of Ghana. Many programs have been put in place including antenatal care, nutrition, Ghana integrated child health campaign and free delivery care policy for pregnant women among others. However, infant mortality is a 
complex phenomenon in that the risk factors are numerous, varied and intertwined. To better deal with infant mortality there is the need to increase understanding about its complexities and this requires a good research to simplify the complex issues surrounding it. The purpose of this study was to examine the prevalence/incidence of hospital-based infant mortality in the military hospital in Ghana, examine the disease-specific causes of infant deaths in the hospital, and determine differentials in infant mortality between male and female infants.

\section{Methodology}

\section{Study design and data collection}

The study was largely quantitative descriptive study where secondary data from a large urban hospital was accessed, reviewed and analyzed. The data included existing vital statistics from birth and birth registry and labor ward. Birth data was compared with mortality data for infants between January and December, 2007. It is important to indicate not all births and death data for the hospital were retrieved by the researcher. Rather, all birth and death data from January to December, 2007 was used for this study because that was when they actually organized their data collection. This helped determined the number and rate of infant mortality for the period as well as gender disparities in infant mortality. The disease specific causes of death for the infants were reviewed from the death records. On clinical risk factors for male and female infant deaths, three professionals were interviewed and their opinions summarized.

\section{Presentation and analysis of data}

Descriptive methods were used to present and analyze data from the study. Monthly infant death figures and disease-specific causes of death are presented with bar graphs/charts while $2 \times 2$ contingency table is used to present infant mortality risk between male and female infants. To determine the sex differences in the burden of infant mortality fisher's exact test and Chi Square with Yates corrections were used to measure the statistical difference between the infant mortality rates for males and females.

\section{Study area}

As stated above, this was a hospital-based study and the selected hospital was 400-bed Military Hospital located in Accra, Ghana. As a military hospital, its primary objective is to provide health care to service personnel and their families (including the Army, Navy and Air Force), civilian employees of the Ministry of Defense and their families and ex-service personnel. Apart from the military personnel, the hospital serves the residents of the entire city and beyond. It is one of the best hospitals in Ghana with modern facilities and has outpatient, emergency and acute care departments and provides referral services. In addition, the hospital serves as the government disaster Hospital and the United Nations Level IV hospital in the West African sub-Region.

\section{Ethical clearance}

The study protocol was reviewed and approved by the institutional review board (IRB) of West Chester University of Pennsylvania. Clearance was also given by the officer in charge of the public health division of the hospital where the study was conducted.

\section{Sources of bias}

In this study there was no bias as the data analyzed had been collected and stored in the hospital long before the study was initiated. The limited data set was retrieved in the presence of the researcher and handed over for entry and analysis.

\section{Results}

The secondary data for the study covered three areas including birth, death and disease-specific cause of death among infants at the military hospital in Ghana in 2007. The review was intended to assess the picture of infant mortality in Ghana as presented in the WHO and CIA rankings of infant mortality in the world. It is important to make it clear that the data presented here are not linked birth and death data. The delivery statistics came from the labor ward while the death data came from birth and death registry. Therefore, there was no data available that linked the deaths to the births. The goal was to make a 
Diagram 1: Infant Mortality by Month and Sex at 37 Military Hospital, Accra. January-December, 2007 (Blue=Male; Red=Female)

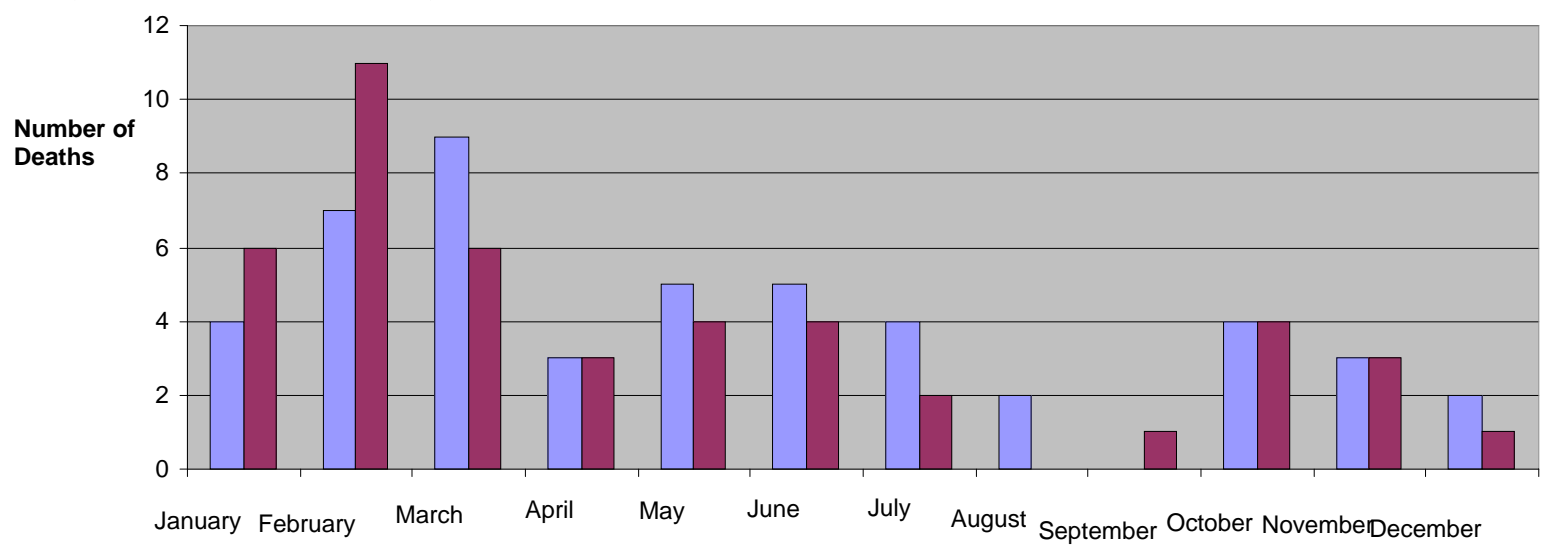

Month and Sex of Infants

general calculation and comparison based on the definition of infant mortality rate.

\section{Births at hospital January-December, 2007}

Based on the delivery data collected at the labor ward, a total of 3,106 babies were born at the hospital between January $1^{\text {st }}$ and December, $31^{\text {st }}$, 2007 in the hospital. Out of this number, 1,612 were males $(52 \%)$ while females were $1,494(48 \%)$. Therefore, there were more male births than females at the hospital in 2007. This number of deliveries in 2007 was unusually high according to the principal nursing officer in charge of the labor ward. She explained that there were series of strike actions by doctors and nurses in government hospitals and health centers throughout the city of Accra and suburban areas in 2007 which resulting in influx of pregnant women at the military hospital.

\section{Infant deaths at the hospital: January- December, 2007}

A review of the death registry data revealed that between January and December, 2007, a total of 98 deaths of infants were recorded in the hospital. This is presented on Diagram 1 in appendix B. There were variations in the number of infant deaths by month and sex in 2007. On the diagram 1 , colors blue and red represented males and females respectively. It can be seen from the diagram that February and March had the highest number of deaths for both male and female infants and became uncertain pattern for the rest of the year. Though not scientifically verified, January and February were the months doctors and nurses in public health institutions went on strike resulting in overcrowding at the military hospital. A general observation of the diagram shows that male infants died more than females. On the $2 \times 2$ contingency table on appendix A, 53 males died (54\%) while 45 females (46\%) died. In analyzing the birth and death data for the year, it was clear that more males were born and equally more males died. The infant mortality rates for males and females calculated were 32.87 and 30.12 per 1000 live births respectively. Fisher's exact test and $X^{2}$ with Yates corrections were used to test the hypothesis that there was no significant difference in infant mortality rates between male and female infants at the hospital. These are represented in Table 1 in the appendix A.

Table 1: 2x2 Contingency Table for Risk of Infant Mortality between Males and Females at 37 Military Hospital for 2007

\begin{tabular}{|c|c|c|c|}
\hline $\begin{array}{ll}\text { Sex } & \text { of } \\
\text { Infant }\end{array}$ & $\begin{array}{l}\text { Infants } \\
\text { Who } \\
\text { Survived }\end{array}$ & $\begin{array}{l}\text { Infants } \\
\text { Who } \\
\text { Died }\end{array}$ & $\begin{array}{l}\text { Total } \\
\text { Delivered } \\
\text { Infants }\end{array}$ \\
\hline Male & 1559 & 53 & 1612 \\
\hline Female & 1449 & 45 & 1494 \\
\hline Total & 3008 & 98 & 3106 \\
\hline
\end{tabular}

Using a two-tailed test, the data was entered into SPSS to calculate Fisher's Exact Test and $X^{2}$ with Yates correction. The $X^{2}$ was 0.113 with 1 degree of freedom and the two-tailed $P$-value of 0.7364 while Fisher's exact test two-tailed $P$-value was 0.6823 . Since both $p$-values were higher than 0.05 
Diagram 2: Disease-Specific Cause of Infant Death at 37 Military Hospital, Accra. January-December, 2007



set for a two-tailed test, statistically, there was no significant difference in infant mortality between male and female infants at military hospital in 2007. Due these results, the researcher failed to reject the null hypothesis that there was no significant difference in the burden of infant mortality between male and female infants in at the hospital.

The birth and infant deaths data for 2007 were also used to calculate the infant mortality rate at the hospital. From the data reviewed, there were 3,106 live births and 98 infant deaths from January to December, 2007. Given that infant mortality rate (IMR) is total deaths of infants divided by total number of live birth multiplied by 1000, the IRM for the hospital in 2007 was 31.55 per 1000 live births. It should be noted that this does not represent a national IMR since the study was hospital based. It does, however, give a general picture of infant mortality problem in Ghana considering that the military hospital is one of the most advanced hospitals in Ghana.

\section{Disease specific cause of death among infants at the military hospital (2007)}

The disease-specific cause of death for the 98 infants who died at the military hospital in 2007 was reviewed. Five major disease/conditions were responsible for the deaths of the infants at the military hospital. Malaria and malaria related conditions accounted for most of the infant deaths. Out of the 98 infant deaths, 29 were due to malaria making up $31 \%$ of all infant deaths at the hospital in 2007. This finding is consistent with report from Ghana reproductive health annual report of 2006 that malaria continues to be the major cause of under-five mortality and morbidity in Ghana ${ }^{3}$. Severe anemia was also a major source of concern for the area and was the second major cause of infant deaths $(23 \%)$, an indication that malnutrition of mothers and babies is still a problem among women and children even in urban centers of the country. Neonatal sepsis was also critical in that $18(20 \%)$ infant deaths were associated to it. This correlates with findings by Prosser and colleagues that neonatal deaths are on the rise in Ghana and becoming greater portion of infant mortality ${ }^{13}$. Congenital heart disease and Respiratory disease were responsible for $9 \%$ and $7 \%$ of infant deaths respectively. Diarrheal diseases which used to be major cause of child mortality in Ghana and sub-Saharan countries as a whole did not cause any infant death at the hospital in 2007. These are represented in Diagram 2 in appendix B.

To test the hypothesis that there is no significant difference in infant mortality risk between male and female infants, a chi square $\left(X^{2}\right)$ test with yate's correction was conducted. The result was that $X^{2}=0.11$ with 1 degree of freedom and $p$-value of 0.74 . Fisher's exact test had two-tailed p-value 0.68 . in both tests, the $p$ value was higher than 0.5 which indicates insignificance and therefore, I failed to reject the null hypothesis.

\section{Discussion}

The results of this study have shown that infant mortality is still a huge public health problem in Ghana and that preventable diseases and/or conditions continue to cause negative health outcomes for infants in the country. The IMR 
(32/1000) live births at in the capital city and at one of the most advanced hospitals in Ghana is an indication that the rural and hard to reach areas of the country will have higher IMRs. This is, therefore, consistent with the report of the GDHS of 2003 that variations within the country are more disturbing and the CIA IMR ranking of Ghana as the $52^{\text {nd }}$ in world ${ }^{6,8}$. Malaria, severe anemia, and neonatal sepsis were found to be the top killers of the 98 infants at the hospital which constituted $31 \%, 23 \%$, and $20 \%$ respectively in 2007. This is also consistent with WHO findings that neonatal diseases accounted for a quarter of infant and child deaths in WHO Africa region and that malaria and diarrhea account for $18 \%$ and $17 \%$ respectively ${ }^{19}$. For instance, in this study malaria was the leading cause of death $(31 \%)$ which is consistent with similar findings ${ }^{13,14,15}$ which found malaria as the main cause of neonatal morbidity and mortality especially in areas of endemic malaria infection. Malaria infection is therefore, dangerous to infant survival either the infant is infected or the mother was infected during pregnancy and time of delivery. This is because malaria exposes pregnant women to severe anemia, reduction in birth weight for infants, preterm delivery, and still birth risk ${ }^{14,16}$. The findings also highlighted the impact and importance of anemia and maternal and infant nutrition on child health in Ghana as $20 \%$ of the infant deaths were attributed to severe anemia. The finding of severe anemia as a major risk factor for infant mortality is also consistent with findings other findings ${ }^{14,17}$. Where by severe anemia during pregnancy was found to result in negative maternal and fetal outcomes. However, the finding of malaria and severe anemia as leading causes of infant death was inconsistent with results of similar study in Trinidad ${ }^{18}$ in which prematurity was found as the leading cause of infant death. In their study ${ }^{18}$, however, neonatal sepsis accounted for $43 \%$ of infant deaths which was consistent with finding in this study of neonatal sepsis as third leading cause of death $(20 \%)$.

This study and similar studies have revealed that undoubtedly malaria is fundamental obstacle in infant survival. It is critical to intensify measures to curtail the rate of malaria infections especially in both infants and pregnant women. In a study to determine sustainability of use of treated insecticide nets and its effects on child survival in Western Kenya ${ }^{4}$ revealed a significant increase in treated net use which translated in significant reduction in infant mortality.

Although, not statistically significant ( $\mathrm{p}$ value 0.73 ) in this study, the burden of infant mortality appears to be more on male (54\%) than female $(46 \%)$ infants and consistent with CIA $^{6}$ finding of IMR for males (56.64/1000) and females is $(47.85 / 1000)$ live births. It is important to note that diarrheal diseases which have traditionally been the leading cause of under-five child mortality in sub-Sahara Africa ${ }^{1,2}$ was not reported as a cause of any of the 98 infant deaths at the hospital in 2007. This is positive indication that there is improvement in management of diarrheal diseases in Ghana, at least in the urban centers.

The limitation in this study is that the data used was secondary and was not collected by the researcher. The researcher did not also know who collected the data and so could not tell the accuracy and completeness of the data. However, the data set was handed over to the research for analysis under strict controls. The researcher only used data set given by the hospital authority and did bring in any bias into the study. Since this study used data from only one urban hospital in Ghana, the findings cannot be generalized for all infant mortality cases in Ghana. However, it is an important indication of the extent of infant mortality and the role of malaria and severe anemia on infant mortality in the country.

\section{Conclusion}

This study has provided an idea of the extent of infant mortality in urban centers in Ghana and highlighted the diseases and/or conditions that threaten the survival of infants in the country as a whole. From the findings, addressing malaria, severe anemia, neonatal sepsis, and other neonatal diseases is required to improving the survival rates of infants in Ghana. The existing malaria control programs should be strengthened and special focus should be put on infants since they are easily overcome by malaria. Maternal and infant nutrition could be improved through emphasis and education on exclusive breastfeeding and importance of balanced diet with locally available food commodities. Finally, research into sex differentials in infant mortality is necessary and effective strategies to identify atrisk infants more precisely for effective interventions for high-risk infants are recommended. 


\section{Acknowledgements}

I owe gratitute to Dr. Gopal Sankaran, a professor of Public Health at the Department of Health at West Chester University of Pennsylvania. He was my academic advisor and guided me on research procedure. I want to also aknowledge the support of Dr. Edward Nyarko, Officer in-Charge of Public Health Division of the 37 Military Hospital. Dr. Nyarko approved and accepted me at the public health division to do my applied learning experience and the study. My gratitude also goes to Madam Hamdaratu Dawuda, a dietian for her assistance in data retrieval and interviews.

\section{Contribution of Authors}

The researcher conceived, planned, and conducted the study alone. A professor of public health helped in editting and reviewing the study protocol and a dietician at the study site assisted the researcher in retrieving data from birth and death registry. These people have been aknowledged above.

\section{References}

1. Smith, Tom A., Regula Leuenberger, and Christian Lengeler. "Child mortality and malaria transmission intensity in Africa." Trends in parasitology 17.3 (2001): 145-149.

2. Jamison, Dean T., et al. "Cost-effective strategies for the excess burden of disease in developing countries." (2006).

3. UNICEF: The State of Africa's Children. 2008. Retrieved July 1, 2008 from http://blogs.uct.ac. za/blog/amandla/2008/07/01/state-of-africa-schildren-2008-unicef.

4. Orrett, Fitzroy A., and Simone M. Shurland. "Neonatal sepsis and mortality in a regional hospital in Trinidad: aetiology and risk factors." Annals of Tropical Paediatrics: International Child Health 21.1 (2001): 20-25.

5. World Health Organization: World Health Statistics, 2007. (2007).Retrieved June 26, 2008 from http:// www.who.int/whosis/whostat2007/en.

6. Central Intelligence Agency: World Fact Book-Ghana
(2008): Rank order-Infant mortality rate. (2008). Retrieved February 8, 2008 from https: //www.cia.gov/library/publications/the-woldfactbook/ranorder/2091 rank.html.

7. World Health Organization. Country System Fact sheet for Ghana. (2007).Retrieved February 10, 2008 from www.afro.who.int/home/countries/fact_sheet /ghana.pdf.

8. Guyatt, Helen L., and Robert W. Snow. "Malaria in pregnancy as an indirect cause of infant mortality in sub-Saharan Africa." Transactions of the Royal Society of Tropical Medicine and Hygiene 95.6 (2001): 569-576.

9. Center for Disease Control: Healthy people 2010. (2008).Retrieved from http://www.cdc.gov/nchs /healthy_people/hp2010/hp2010_final_review.htm.

10. Ghana Statistical Service. Ghana demographic and health Survey (2003). ORC Marco, Calverton, Maryland. 2004.

11. Prosser, Michelle, et al. "The emerging midwifery crisis in Ghana: mapping of midwives and service availability highlights gaps in maternal care." United States Aid for International Development (2006).

12. Reidpath, Daniel D., and Pascale Allotey. "Infant mortality rate as an indicator of population health." Journal of epidemiology and community health 57.5 (2003): 344-346.

13. Lindblade, Kim A., et al. "Sustainability of reductions in malaria transmission and infant mortality in western Kenya with use of insecticide-treated bednets: 4 to 6 years of follow-up." Jama 291.21 (2004): 2571-2580.

14. Public Agenda: Ghana has the 32nd highest child mortality in the world. (2008). Retrieved February 18, 2008 from http://allafrica.com/stories/200801 250639.html.

15. UNICEF: Ghana's Integrated Child Health Campaign. (2006). Retrieved July 30, 2008 from https://www. unicef.org/media/files/Ghana_Integrated_Health_C ampaign.pdf.

16. Hammer, Gaël P., et al. "Pattern of cause-specific childhood mortality in a malaria endemic area of Burkina Faso." Malaria journal 5.1 (2006): 47.

17. Geelhoed, Diederike, et al. "Maternal and fetal outcome after severe anemia in pregnancy in rural Ghana." Acta obstetricia et gynecologica Scandinavica 85.1 (2006): 49-55.

18. Poespoprodjo, Jeanne Rini, et al. "Adverse pregnancy outcomes in an area where multidrug-resistant Plasmodium vivax and Plasmodium falciparum infections are endemic." Clinical Infectious Diseases 46.9 (2008): 1374-1381. 